\title{
Adenda a evolución cronológica del trasplante renal en España
}

\author{
Pérez Albacete M.
}

Servicio de Urología. Hospital Universitario Virgen de la Arrixaca. Murcia.

Actas Urol Esp. 2007;31(4):423-425

\section{Sr. Director:}

Me remite el Dr. José María Gil-Vernet unas puntualizaciones en relación con el artículo "Evolución cronológica del trasplante renal en España", aparecido en el volumen XXX, número 8, del mes de septiembre de 2006 y me facilita unas anotaciones correctoras que amplian y mejoran la información suministrada. Considero de gran interés su publicación para darlas a conocer, dado que son datos de primera mano, como complemento al conocimiento del desarrollo del trasplante renal en España.

En el Hospital Clínico de Barcelona se creó en 1963 la primera Unidad de Trasplantes en España dirigida por el urólogo Dr. D. José María Gil-Vernet y el nefrólogo Dr. D. Antonio Caralps. En los dos primeros años completaron un protocolo experimental en animales, primero en laboratorios químicos, en los que probaron con diversos liquidos de perfusión a distintos grados $\mathrm{y}$ tiempos de hipotermia la conservación de órganos y, después, en cirugía experimental en el Zoológico y en la Facultad de Farmacia en donde se trasplantaron riñones, páncreas y gónadas.

Esta investigación quirúrgica le permitió a Gil-Vernet crear dos nuevas técnicas de trasplante renal, una heterotópica y otra ortotópica, que son distintas a la convencional utilizada por los Drs. Küss y Murray, ya que con aquellas se trasplanta el riñón y utiliza la totalidad del uréter del receptor que conserva, por tanto, su inervación y vascularización junto con el mecanismo ureterovesical antirreflujo y el marcapasos de la unión pieloureteral; restablece la continuidad urinaria con una pielo-pielostomía micro quirúrgica (Fig. 1) y no deja catéter de drenaje, puesto que de inmediato se consigue una urodinamia normal. La vena renal la anastomosa a la cava con lo que se consigue un mejor retorno venoso. En el trasplante heterotó-

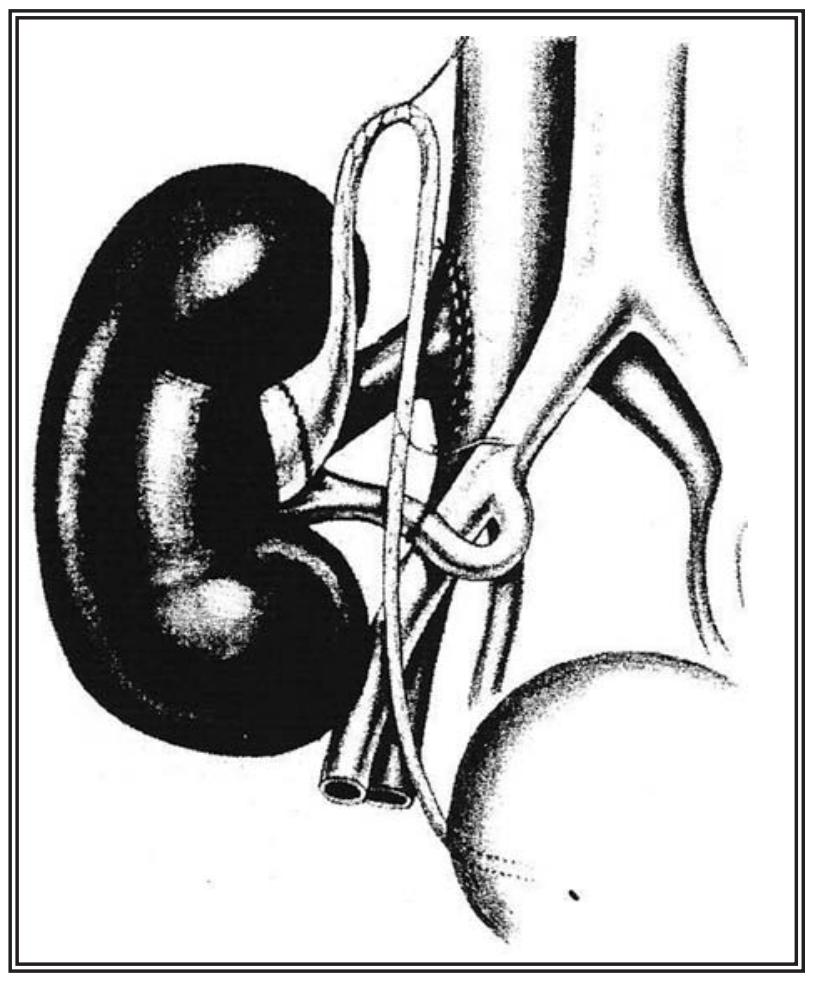

FIGURA 1. Esquema de la primera técnica de trasplante del Dr. Gil-Vernet, de 1965. Anastomosis pielo-piélica, la vena renal a la vena cava y la arteria renal a la iliaca. Se aprecia en la curva del uréter cómo conserva su pediculo arterial.

pico el riñón queda en posición normal en situación lumbo ilíaco $\mathrm{y}$, si se utiliza un riñón derecho, se encuentra invertido ${ }^{1,2}$.

Con este procedimiento, y con un riñón de cadáver, se logró el 23 de julio de 1965, el primer trasplante renal con éxito en España (Fig. 2), tras el cual, realizó otros 456 entre ellos el de un paciente que, con un riñón de su hermano univitelino, es de los de mayor supervivencia del mundo, 37 años (Fig. 3), con absoluta normalidad funcional y urodinámica y con una creatinina plasmática de 1,4 mg. (Fig. 4). Esta técnica mereció el Premio Nacional de Cirugía en 1967. 


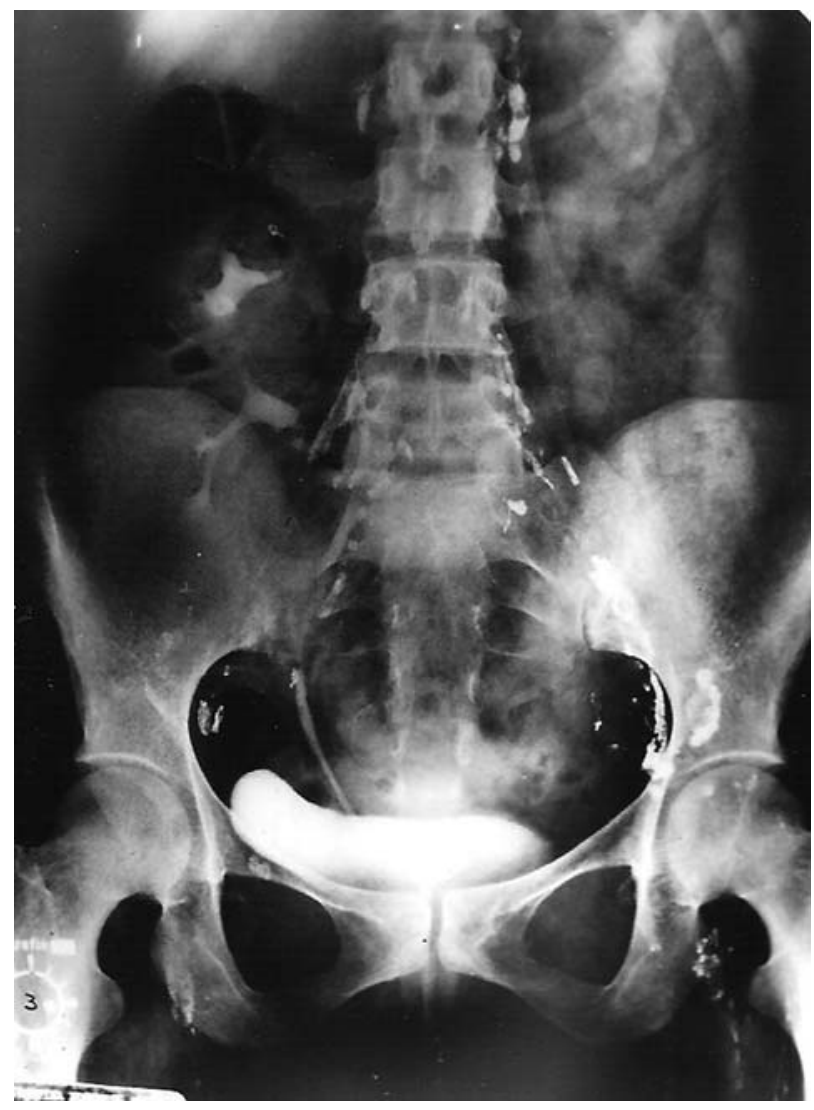

FIGURA 2. Urografia original del primer trasplante renal de cadáver con éxito.

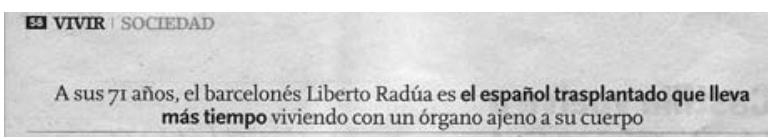

\section{7 años con el riñón de su hermano}

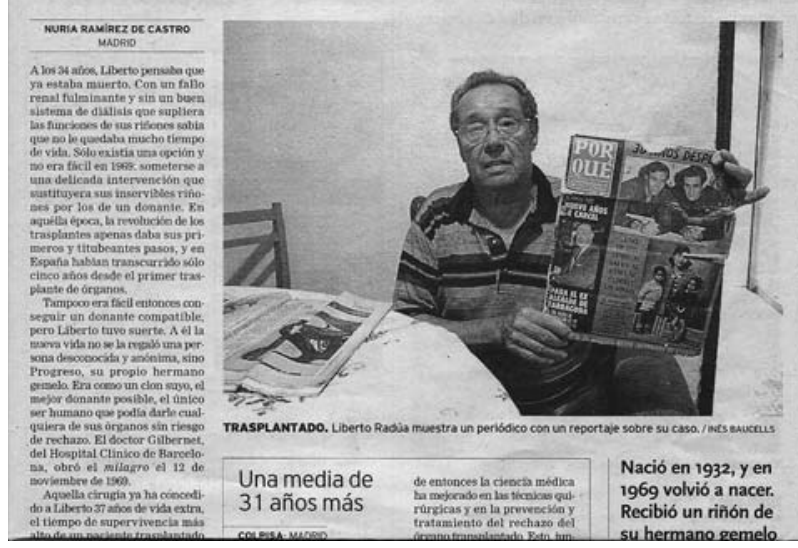

FIGURA 3. Paciente trasplantado hace 37 años.

Sin embargo Gil Vernet acepta que, si bien esta técnica consigue los mejores resultados hemo y urodinámicos, es más compleja y difícil en su ejecución y exige un mayor esfuerzo y pre-

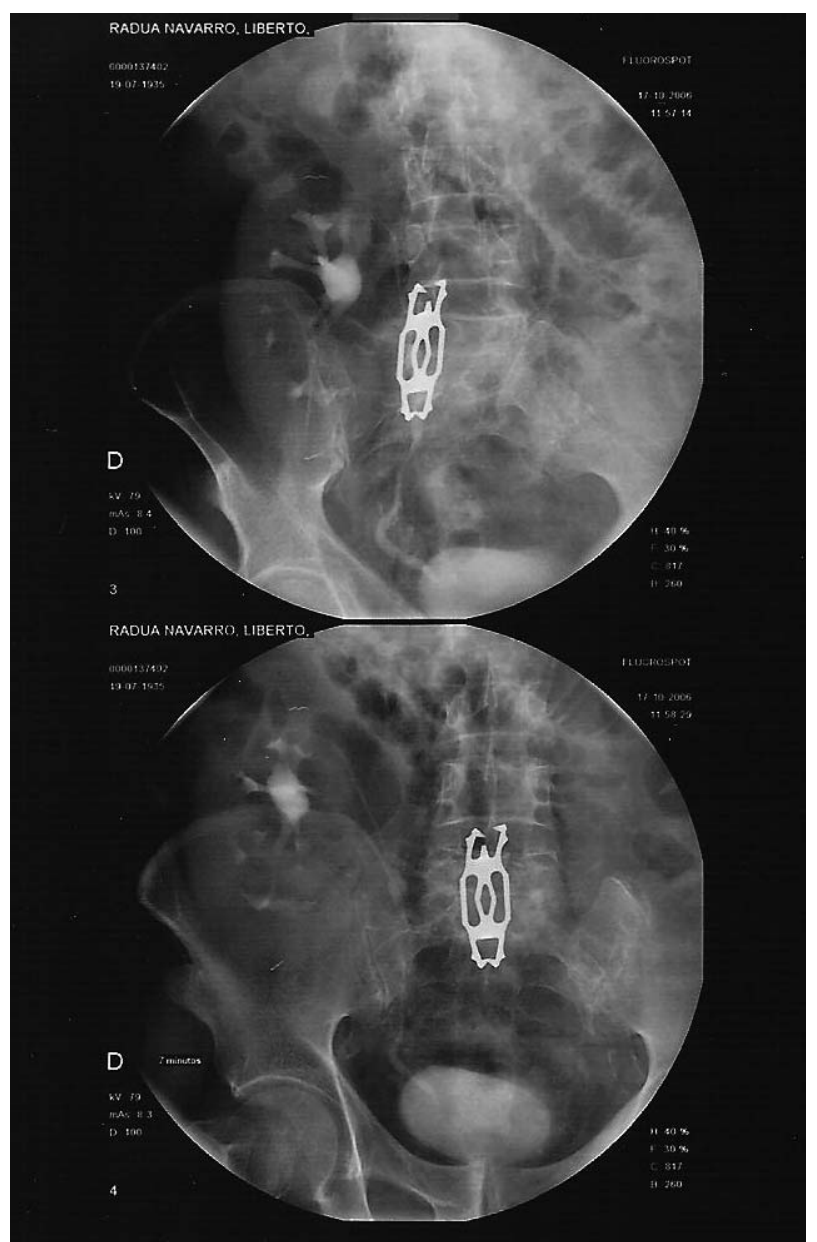

FIGURA 4. Urografias a los 37 años del trasplante renal (2006).

paración por parte del cirujano. Admite que la creciente demanda de trasplantes renales ha hecho necesario universalizar un procedimiento que sea asequible a todos los cirujanos y en este sentido la técnica convencional de Küss y Murray lo es. Actualmente existe acuerdo en utilizar este procedimiento para rescatar aquellos riñones trasplantados con serias complicaciones a nivel de uréter ${ }^{3}$.

Su segunda técnica fue la del trasplante renal ortotópico (TRO), gracias a su descubrimiento, en el año $1978^{4}$, de una nueva vía de abordaje lumbar extraperitoneal a los vasos esplénicos y que significó un importante avance en el tratamiento de la revascularización renal y en la cirugía de la hipertensión portal.

En el TRO el riñón queda en la situación anatómica que le es propia, está más protegido, con- 
serva toda la vía excretora (anastomosis pielopiélica), con su inervación y vascularización y mantiene una uro y hemodinámicas normales ${ }^{5}$. Si el calibre de la arteria esplénica no es adecuado prefiere la anastomosis de la arteria renal con el ostium renoaórtico del riñón patológico extirpado lo que proporciona un mejor flujo sanguíneo. No es una técnica de rutina, pero es una alternativa válida y utilizada en problemas de la cava o de las ilíacas y, en particular, en el tercer retrasplante. Según su autor, en el TRO no existe la llamada patología del uréter trasplantado.

\section{REFERENCIAS}

1. Gil-Vernet JM, Caralps A. Human renal homotrasplantation. New surgical technique. Urol Int. 1968;23(3):201-223.
2. Hamburger J, Crosnier J, Dormont J, Bach JF. La transplantation rénale. Théorie et pratique. Flamarion Médecine Sciences, 1971 París.

3. Wagner M, Dieckmann KP, Klän R, Fielder U, Offermann G. Rescue of renal transplant with distal ureteral complications by pyelo-pielostomy. J Urol. 1994;151:578-581.

4. Gil-Vernet JM, Caralps A, Ruano D. New approach to the splenic vessels. J Urol. 1978;(119):313-315.

5. Gil-Vernet JM, Gil-Vernet A, Caralps A, Carretero P, Talbot Wriht R. Andreu J, et al. Orthotopic renal transplant and results in 139 consecutive cases. J Urol. 1989;142(1):248252.

Correspondencia autor: Dr. M. Pérez Albacete

Servicio de Urología. Hospital Universitario Virgen de la Arrixaca. Ctra. Madrid-Cartagena, s/n. 30120 El Palmar. Murcia Tel.: 969369779

E-mail autor: mariano.perez2@carm.es Información artículo: Cartas al director Trabajo recibido: febrero 2007

Trabajo aceptado: marzo 2007 